common drug used at last overdose. Of the resuscitation methods reported at last personal overdose, none included naloxone administration. Knowledge of the correct signs of overdose was similar pre- and post-video (97\% pre vs. $100 \%$ post, $\mathrm{p}=0.32$ ). The proportion of responders correctly answering overdose risks $(51 \%$ pre vs. $89 \%$ post, $\mathrm{p}<0.001)$, proper use of naloxone $(46 \%$ pre vs. $100 \%$ post, $\mathrm{p}<0.001)$, and order of resuscitation steps $(49 \%$ pre vs. $86 \%$ post, $\mathrm{p}<0.001)$ significantly improved post-video.

Conclusions Many AYA with severe opioid use disorders have witnessed overdoses, and naloxone appears to be underutilized in this population. Although overdose signs were well recognized, naloxone resuscitation mechanisms were not well understood. A brief video at time of prescription significantly improved knowledge of proper use of naxolone. Future study should investigate whether increased knowledge results in improved naloxone use.

\section{P41 INNOVATIVE EXPERIENTIAL PROGRAMMES ADDRESSING CYBER SHAMING AND BULLYING: A WORK IN PROGRESS}

${ }^{1,2} \mathrm{D}$ Hardoff* ${ }^{2,3} \mathrm{D}$ Amsalem, ${ }^{2,3,4} \mathrm{D}$ Gothelf, ${ }^{5} \mathrm{M}$ Shraga, ${ }^{1,2} \mathrm{~L}$ Pesshach-Gelblum, ${ }^{1,2,4} \mathrm{~A}$ Ziv ${ }^{1}$ Israel Center for Medical Simulation, Tel Hashomer, Ramat Gan, Israel; ${ }^{2}$ Chaim Sheba Medical Center, Tel Hashomer, Ramat Gan, Israel; ${ }^{3}$ Child and Adolescent Psychiatry Unit, Tel Hashomer, Ramat Gan, Israel; ${ }^{4}$ Sackler Faculty of Medicine, Tel Aviv University, Tel Aviv, Israel; ${ }^{5}$ Openmind 360, Aviel, Israel

\subsection{6/bmjpo-2019-RCPCH-SAHM.45}

Aims We describe two experiential programmes toward school shaming and bullying $(\mathrm{S} / \mathrm{B})$, aiming at prevention, identification and early intervention.

Methods Teachers attended a 2-day train-the-trainer workshop. 1stday: 8 simulation-based S/B scenarios, where communication with pupils and with parents role-played by actors was exercised. Teacher-actor encounters were video-recorded to be screened during debriefing sessions. 2nd day: Teachers were trained to conduct school discussions on S/B with other school staff, utilizing video-recordings of their own training. Teachers completed a 4-grade-Likert-scale questionnaire rating the workshop's quality, value, and relevance for approaching S/B situations, as well as open ended questions regarding their workshop's experience.

Results 91 teachers attended 6 train-the-trainer workshops. The average rates for the workshop's quality, value, and relevance were $3.86,3.57$ and 3.71 respectively. A unanimous satisfaction was expressed with a plea for further training and professional supervision. Work in progress: Following the teachers' programme, we developed an S/B experiential oneday workshop for secondary school pupils. It included: a. An Internet-based-survey regarding psychological effects of $\mathrm{S} / \mathrm{B} ; \mathrm{b}$. A child psychiatrist's talk on outcomes related to $S / B$ victims. Perpetrator-victim characteristics were emphasized and tools for identifying and coping with S/B were suggested; c. A virtual-reality scenario (developed in collaboration with Openmind 360 Inc.) of cyber-shaming that allows the viewer to choose different pathways that may follow the shaming situation. A social worker led a discussion about the shaming scenario and the alternative pathways; d. A stage performance: a teenage boy (actor) proudly tells a friend about himself bullying another boy. He then admits being a violence victim at home. A discussion of the scenario was led by a school counselor; e. A discussion based on the results of the pupils'pre- lecture survey and the experiential exposure in each group concluded the workshop. In the course of 2 school years 690 10 th grade pupils (48 groups) attended the programme. Analysis of the pre-workshop surveys and the workshops' impact within the schools is in progress.

Conclusions Simulation-based educational programmes addressing $\mathrm{S} / \mathrm{B}$ for both teachers and pupils were valued as relevant and helpful for prevention, identification and early intervention. Long-term evaluation of their effectiveness is in progress.

\section{P42 $\quad$ YPAGNE - ENGAGEMENT AND INVOLVEMENT. ENSURING THE VOICE ON YOOUNG PEOPLE IS HEARD}

J Ball ${ }^{*}$, N Davidson. Children's Services, Newcastle Hospitals NHS Trust, Newcastle upon Tyne, UK

10.1136/bmjpo-2019-RCPCH-SAHM.46

Aim To imbed the voice of young people in research design and delivery in order to improve input and influence of young people (YP) in the development of clinical and public health research.

Methods YPAGne hold regular meetings, employ innovative facilitation strategies that draw on skills from youth work, patient and public involvement and engagement (PPIE) techniques and participatory design methods. YPAGne captures instant feedback from members and visiting teams using innovative technology developed with colleagues at Newcastle University. The group also adopts tight cycles of reflection to improve the YPAGne participatory approach on a month-tomonth basis. Innovation is at the core of YPAGne' $s$ DNA and we have the privilege of working with a truly dynamic and thoughtful group of young innovators who want to see the health of the nation improved through their input. The success of the group is built on a strong management team which employs a distributed model of leadership and reflective practice to ensure the group continues to push boundaries and grow.

Results Research studies with PPIE involvement and engagement in YPAGne develops life skills, increases confidence, resilience and self-esteem almost by stealth. Members join out of curiosity, parent persuasion and UCAS application impact; they stay because they have an opportunity to make a difference, to be involved in decision making and are listened to.

Conclusion YPAGne has attracted the attention of not just researchers, funders and national bodies but young people from around our region are hearing about how they can make a real difference to health in their nation. Involvement in groups such as YPAGne helps young people with resilience, increases confidence and equips them with valuable skills.

\section{P43 MODELLING THE IMPACT OF CALORIE-REDUCTION INTERVENTIONS ACROSS THE RANGE OF DEPRIVATION}

SJ Russell* , S Hope, H Croker, J Packer, RM Viner. Institute of Child Health, University College London, London, UK

\subsection{6/bmjpo-2019-RCPCH-SAHM.47}

Aims Given that overweight and obesity are primarily caused by an energy-rich and low nutrient diet which contributes to a positive net energy imbalance, the primary aim of this study 